
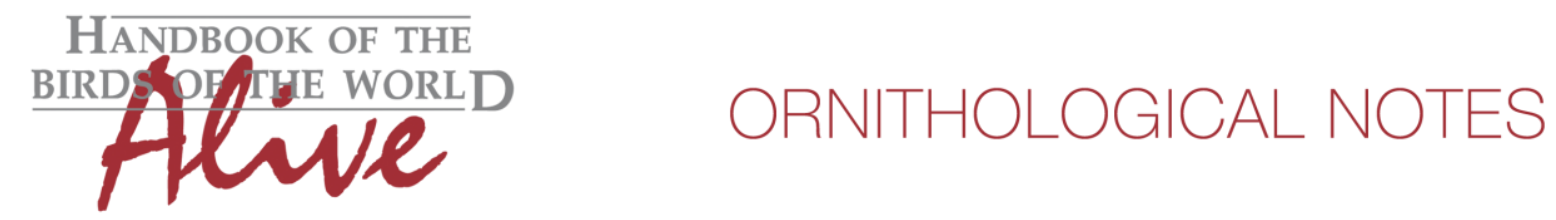

\title{
Notes on the vocalizations of Black-billed Thrush (Turdus ignobilis)
}

Peter Boesman

In the following we briefly analyze and compare voice of the different races of Black-billed Thrush (Turdus ignobilis). We also try to quantify the extent of any vocal differences using the criteria proposed by Tobias et al. (2010), as a support for taxonomic review.

We have made use of sound recordings available on-line from Xeno Canto (XC) and Macaulay Library (ML).

Based on genetic information, it is suggested this complex consists of several cryptic species with different habitat requirements (Cerqueira et al. 2016). As apparently some taxa were not included in this study, and consequently it is not clear to which group they may pertain, we will analyze voice per taxon. There is however often quite some uncertainty to which taxon recordings belong, as there are apparently several areas of sympatry (albeit in different habitat), and on top of that, given that song is mainly uttered at dawn, there is some uncertainty about correct identification as well (confusion with other Turdus species). Furthermore, HBW Alive seems to have confused distribution of murinus and arthuri (Collar \& Bonan 2016).

Some examples of song per race, illustrated with sonograms:

T. i. goodfellowi (Andes of W Colombia).

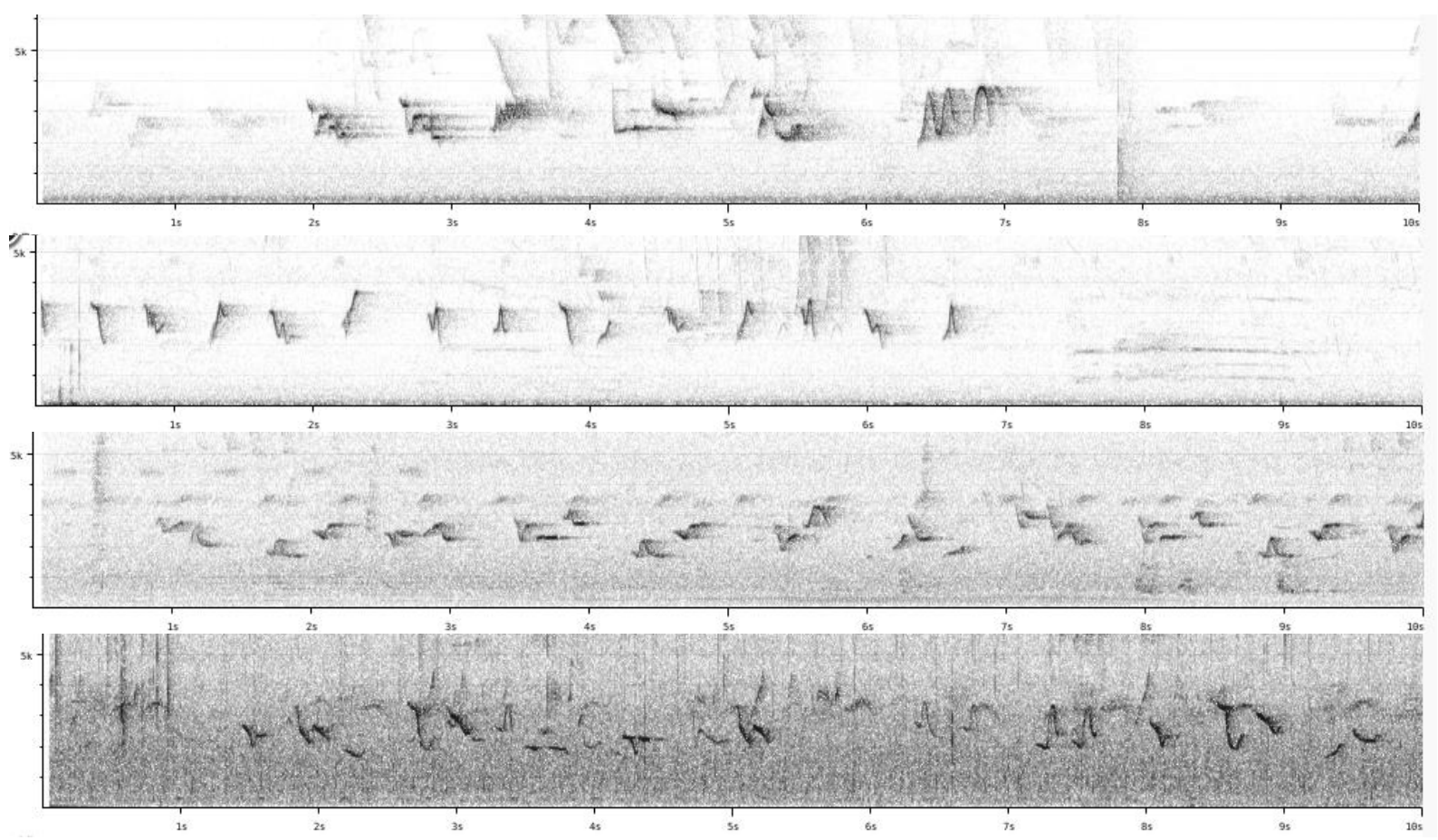




\section{HANDBOOK OF THE \\ Alve}

\section{ORNITHOLOGICAL NOTES}

T. i. ignobilis (Andes of C \& E Colombia).

Tolima

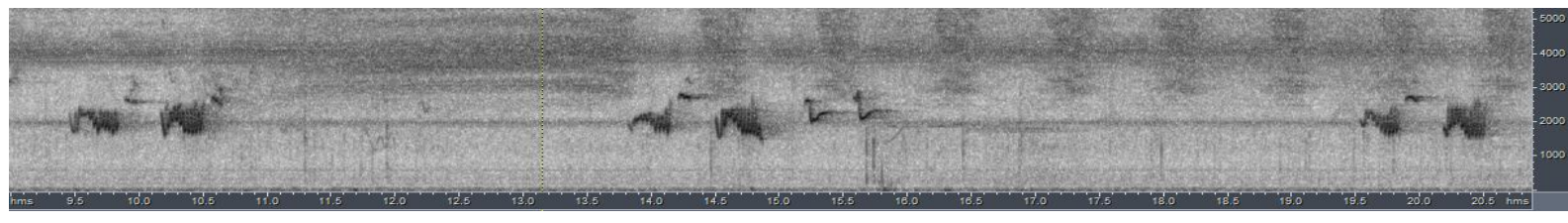

T. i. arthuri (?) (savannas of S Venezuela, Guyana and Suriname)

Suriname (Kraka, white sand in lowland)

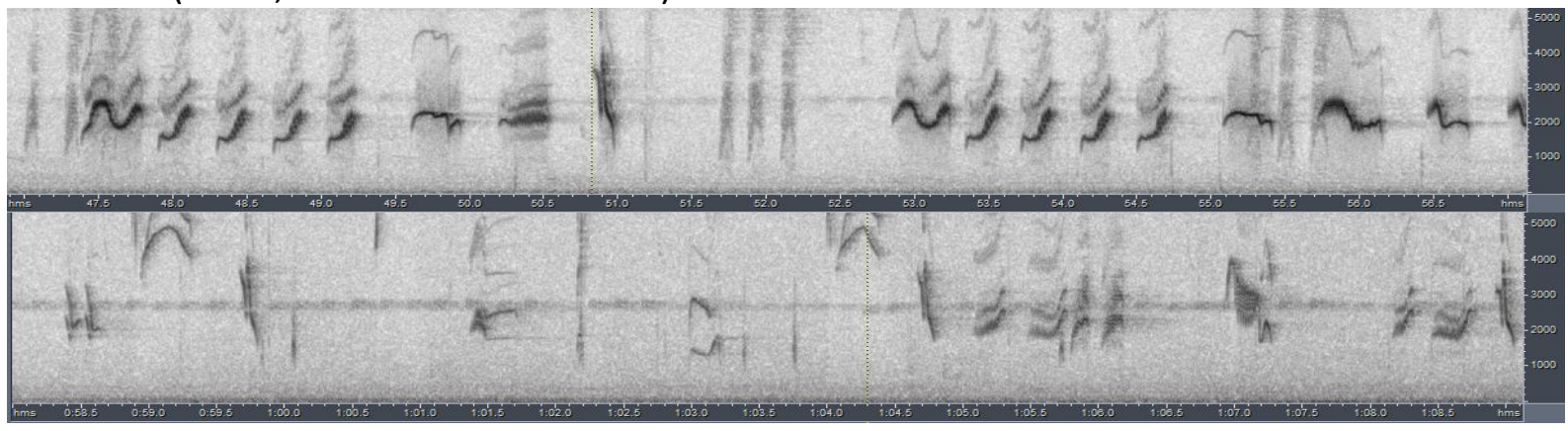

T. i. debilis (E Colombia, W Venezuela, and W Amazonia in Brazil, E Ecuador, E Peru and N Bolivia).

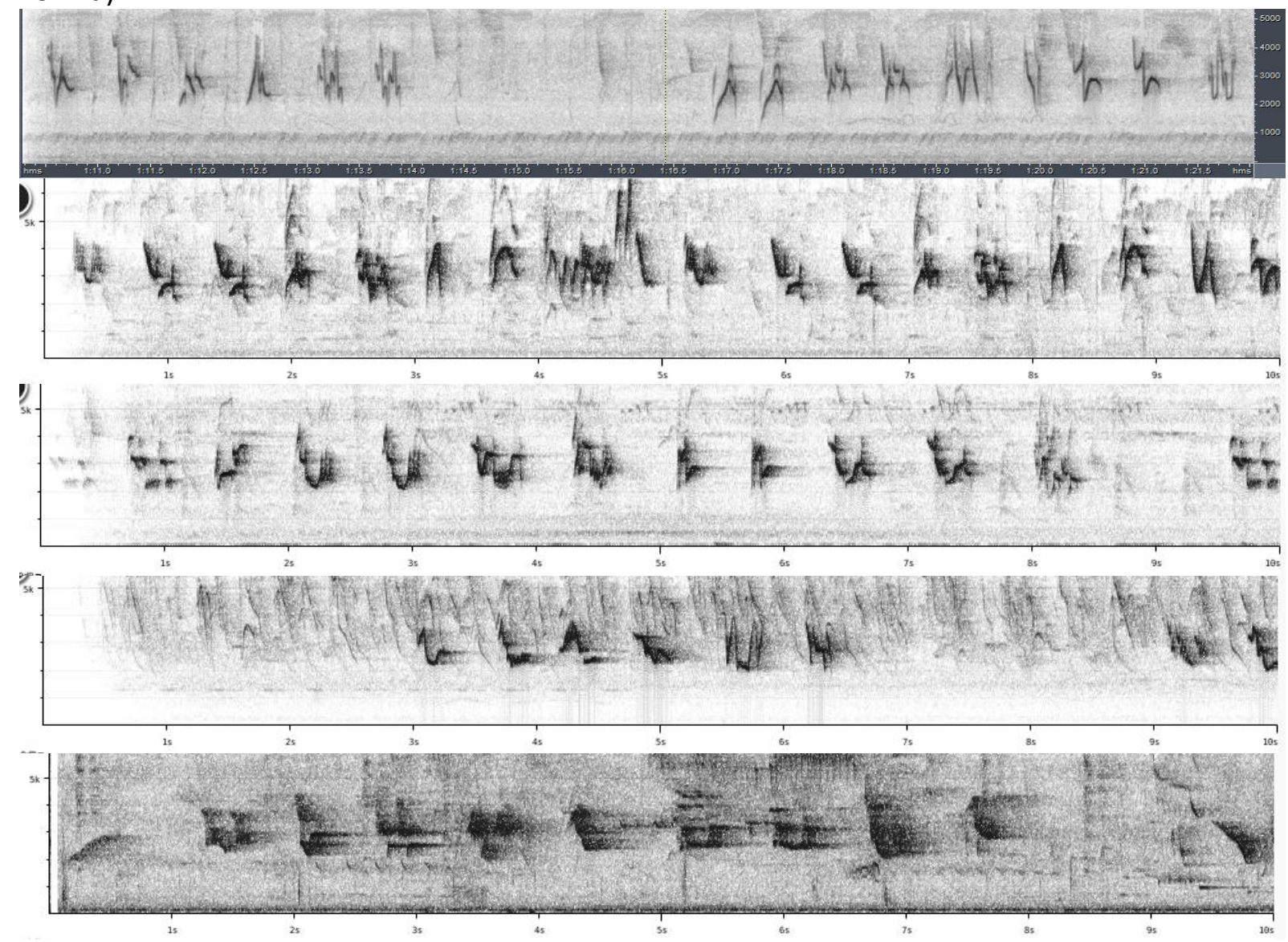



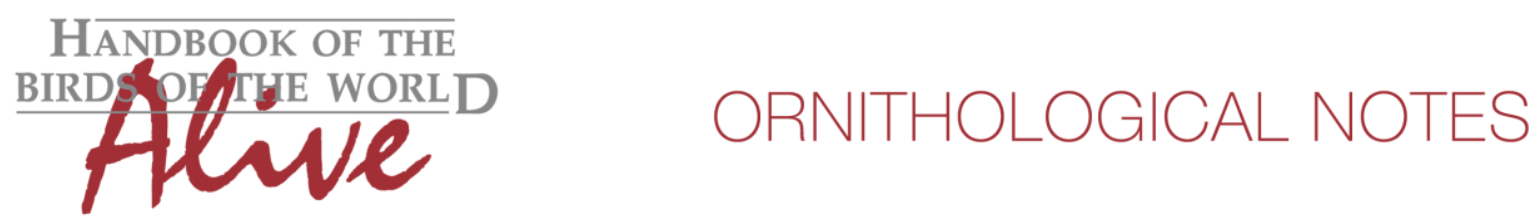

T. i. murinus (?) (Tepuis of SE Venezuela, Guyana). (+T.i.cururuensis)

No recordings available. Hilty (2003) describes song with some differences vs. debilis, including call notes.

With the sparse material available, it is far from straightforward to draw any conclusions about vocal differences.

debilis, the best documented taxon, has a leisurely song of single complex notes given one by one at a steady pace. Often a note is repeated once again before changing to a next different note. All notes have a fairly broad frequency range (c. $2 \mathrm{kHz}$ ).

Birds of the Colombian W Andes (Cauca valley)(goodfellowi?) seem to have quite a different song with much simpler notes, with a slightly narrower frequency range.

Birds from the white sand savanna in Suriname (arthuri) have a much more dynamic song with accelerations, fast repeats etc., being thus quite different from both previous taxa.

Not much can be said about the races ignobilis and murinus.

All in all, there is too little information available about song to draw firm conclusions, but it seems very likely that several species are involved!

A more in depth study is definitely needed once more recordings of song become available, and obviously call notes may hold additional information.

This note was finalized on 20th April 2016, using sound recordings available on-line at that moment. We would like to thank in particular the sound recordists who placed their recordings for this species complex on XC and ML.

\section{References}

Cerqueira, P.V., Santos, M.P.D. and Aleixo, A. (2016). Phylogeography, inter-specific limits and diversification of Turdus ignobilis (Aves: Turdidae). Mol. Phylogenet. Evol. 97: 177-186.

Collar, N. \& Bonan, A. (2016). Black-billed Thrush (Turdus ignobilis). In: del Hoyo, J., Elliott, A., Sargatal, J., Christie, D.A. \& de Juana, E. (eds.). Handbook of the Birds of the World Alive. Lynx Edicions, Barcelona. (retrieved from http://www.hbw.com/node/58291 on 20 April 2016).

Hilty, S.L. (2003). Birds of Venezuela. Helm Field Guides. Christopher Helm. London.

Tobias, J.A., Seddon, N., Spottiswoode, C.N., Pilgrim, J.D., Fishpool, L.D.C. \& Collar, N.J. (2010). Quantitative criteria for species delimitation. Ibis 152(4): 724-746. 


\section{Recommended citation}

Boesman, P. (2016). Notes on the vocalizations of Black-billed Thrush (Turdus ignobilis). HBW Alive Ornithological Note 309. In: Handbook of the Birds of the World Alive. Lynx Edicions, Barcelona. (retrieved from http://www.hbw.com/node/1251825 on 15 October 2016). 